\title{
Mediação: um meio de desjudicializar a saúde.
}

\author{
Mediation: a way to disjudialize health.
}

Mediacion: un medio de desjudicializar la salud.

Maria dos Remédios Mendes OLIVEIRA ${ }^{1}$ Maria Célia DELDUQUE²

Maria Fátima de SOUSA ${ }^{3}$

Ana Valéria Machado MENDONÇA ${ }^{4}$

RESUMO: O artigo analisa o direito à saúde como direito fundamental inserto na Constituição do país e ainda não executado plenamente pelo Estado. Discute como as demandas tem superlotado os Tribunais de Justiça, provocando os gestores públicos governamentais, no âmbito do Sistema Único de Saúde, em busca de respostas as demandas sentidas pelos indivíduos, famílias e comunidades no tocante ao acesso as ações e serviços de saúde, ou seja, discorre sobre o que o cidadão de forma individual ou coletiva busca através da via judicial garantir e efetivar o seu direito à saúde. Apresenta outros elementos para o debate contemporâneo acerca da efetividade do direito à saúde, reconhecendo-o como um conjunto de respostas políticas e ações governamentais mais amplas, e não meramente formais e restritas às ordens judiciais. Sugere outros elementos para ampliar o debate no entorno da judicialização no setor saúde. Ressalta que o instituto da mediação pode ser um instrumento potencial a abertura ao diálogo entre os poderes judiciários e executivos, como estratégia para a desjudicialização da saúde.

Palavras-Chave: Judicialização da saúde; Acesso a bens e serviços de saúde; Direito à saúde; Mediação.

ABSTRACT: The article analyzes the right to health as a fundamental right inserts in the Constitution and not yet fully implemented by the state. Discusses how the demands have crowded the Courts of Justice, causing the government public managers within the National Health System, in search of answers the demands felt by individuals, families and communities in gaining access to the actions and health services, or is, discusses what the citizen individually or collective search by judicial process secure and carry their right to health. It has other elements to the contemporary

1 Universidade de Brasília (UnB) - Brasília (DF), Brasil. E-mail: remediosmendes@hotmail.com 2 Fundação Oswaldo Cruz (Fiocruz) - Brasília (DF), Brasil. E-mail:mcdelduque@gmail.com 3 Universidade de Brasília (UnB) - Brasília (DF), Brasil. E-mail: mariafatimasousa@uol.com.br 4 Universidade de Brasília (UnB) - Brasília (DF), Brasil. E-mail:valeriamendonca@unb.br 
debate about the effectiveness of the right to health, recognizing it as a set of policy responses and broader government action, not merely formal and restricted to court orders. Suggests other elements to broaden the debate surrounding the legalization in the health sector. Points out that the mediation of the institute can be a potential tool to open dialogue between the judicial and executive powers, as a strategy for desjudicializaçãohealth.

Key words: Judicialization of Health; Access to goods and services of health; Right to Health; Mediation.

RESUMEN: El articulo analizaelderecho a lasalud como derecho fundamental insertada enlaconstitucióndel país y aun no fueejecutada plenamente por el estado, discuten como las demandas tienenllenoslosTribunales de Justícia, provocando a los servidores públicos gubernamentalesenelámbito único del sistema de saluden busca de respuestas a las demandas de losindividuos, familias y comunidades conrespecto al acceso a lasacciones y servicios de salud, o sea que discute lo que elciudadanoen forma individual o colectiva busca atreves de lavía judicial para garantizar y hacerefectivasuderecho a lasalud, presenta otros elementos para el debate actual acerca de laefectividaddelderecho a lasalud, reconociéndolo como un conjunto de respuestas políticas y accionesgubernamentales más amplias, y no meramente formal y restringido a lasórdenesjudiciales, sugiereotros elementos para ampliar el debate entorno a lajudicializaciónenel sector salud, Se señala que lamediacióndel instituto puede ser una herramienta potencial para abrir el diálogo entre los poderes judicial y ejecutivo como estrategia para ladesjudicialización de lasalud.

Palabras clave: Judicialización de lasalud, acceso a losbienes y servicios de salud, Derecho a lasalud, mediación.

\section{INTRODUÇÃO}

Este artigo tem como objetivo descrever de forma analítico - reflexiva o direito à saúde, assegurado pela Constituição Federal-CF de 1988 e ainda a judicialização da saúde, fenômeno que provoca o Poder Público a criar políticas públicas para dar cumprimento as atribuições do Estado, insertas na CF, e do Supremo Tribunal Federal - STF, instância máxima do Poder Judiciário, a necessidade de compreender para melhor decidir.

A relevância do tema é corroborada pelo momento atual em que a conquista do direito à saúde, assegurado há 27 anos pelo artigo 196 da Constituição Federal promulgada em 1988', não foi concretizado com o acesso a bens e serviços de saúde no âmbito do Sistema Único de Saúde-SUS.

Pode-se, então, afirmar que o SUS garantido pela Constituição Federal e leis orgânicas Lei $\mathrm{n}^{\mathrm{o}} 8.080^{5}$, de 19 de setembro de 1990 , pela Lei $\mathrm{n}^{\mathrm{o}} 8.142^{6}$, de 28 de dezembro de 1990 com seus

5 Dispõe sobre as condições para a promoção, proteção e recuperação da saúde, a organização e o funcionamento dos serviços correspondentes e dá outras providências. Alterada pelas Leis no s. 9.836, de 24.9.1999 e 10.424, de 16.4.2002. 6 Dispõe sobre a participação da comunidade na gestão do Sistema Único de Saúde - SUS e sobre as transferências intergovernamentais de recursos financeiros na área da saúde e dá outras providências.

Tempus, actas de saúde colet, Brasília, 10(1), 169-177, mar, 2016.

ISSN 1982-8829 
princípios doutrinários e preceitos constitucionais de universalidade (acesso da população a qualquer serviço de saúde); equidade (acesso em igualdade de condições aos diferentes níveis de complexidade do sistema) e integralidade (ações integrais e não mais fragmentadas) representam um grande avanço no projeto de Reforma Sanitária Brasileira ${ }^{2}$. Entretanto, tem sido insuficiente para promover as transformações necessárias à construção de um novo modelo de atenção à saúde integral aos indivíduos, famílias e comunidades, conforme afirma Sousa ${ }^{3}$. Ainda segundo a autora, o Brasil no tocante as questões básicas como a igualdade dos cidadãos diante da lei e a necessidade de incluir os excluídos na comunidade de direitos seguem pendentes, na medida em que o país continua enfrentando, simultaneamente, antigos e novos desafios que se apresentam no desenvolvimento da cidadania. Estas contradições são responsáveis por distintos graus de desenvolvimento destes direitos. As diferenças se dão, nos dizeres de Fleury ${ }^{4}$, tanto no tempo quanto no conteúdo e extensão, envolvendo um processo contínuo de redefinição da concepção de cidadania.

De igual maneira, os direitos envolvidos na noção de cidadania são de natureza muito distinta, alguns deles implicando em restrições à ação do Estado, como no caso dos direitos civis, enquanto outros requerem uma intervenção do mesmo, como os direitos sociais. Segundo Bobbio ${ }^{5}$ todo e qualquer direito sejam de um povo ou de um indivíduo, só se afirma através de uma disposição ininterrupta para a luta. Para ele, que adota uma posição firme contra a ideia dos direitos naturais, os direitos nascem quando devem e podem nascer. São direitos históricos, que surgem em circunstâncias determinadas, relacionadas com a defesa de novas liberdades e capacidades dos sujeitos sociais de compreenderem-se com sujeitos de ação política. Essa como estratégia capaz de enfrentar o aparelho de Estados e os governos instituídos em busca permanente dos seus direitos.

Nesse sentido, a via judicial é o meio encontrado pelos sujeitos que de forma individual ou coletiva recorrem ao Poder Judiciário para garantir que seus direitos sejam assegurados e concretizados.

Ao garantir a saúde como direito de todos e dever do Estado, a CF de 1988 possibilitou o empoderamento dos sujeitos oriundos de classes sociais com pouca concentração de renda e reduzido acesso à educação e à cultura; assim, a sociedade empoderada procura fazer valer o direito constitucional recorrendo ao judiciário em duas dimensões distintas: de forma individual e de forma coletiva, ocasionando um enorme volume de demanda judicial por bens e serviços de saúde, gerando sobrecarga de trabalho nos tribunais brasileiros. $\mathrm{O}$ acesso à justiça vem funcionando como verdadeiro conduto de cidadania. Essa explosão de demandas judiciais, denominada de fenômeno da judicialização, teve reflexo imediato: a crise do Poder Judiciário que, por si só, não é suficiente para atender a grande demanda existente e já não responde com eficiência na solução dos conflitos no campo da saúde.

Neste trilho, o presente estudo busca ampliar o debate acerca do instituto da mediação, como um instrumento potencial à abertura ao diálogo entre os poderes Judiciário e Executivo, regulada em Lei recentemente, como meio que pode ser eficaz para a desjudicialização da saúde. 


\section{SAÚDE, UM DIREITO FUNDAMENTAL}

Sousa ${ }^{3}$ ao citar Bobbio ${ }^{5}$ recorda do pensamento de Hanna Arendt $^{6}$,quando a autora nos provoca a refletir sobre a igualdade de direito. Essa promovida pelas instâncias governamentais, nesse particular o Sistema Único de Saúde, e sua missão social de assegurar o direito aos bens e serviços de saúde. Reforça Arendt ${ }^{5}$, as esferas públicas são politicamente construídas, já que na natureza humana o que encontramos é a diferença. A cidadania, hipótese jurídica igualitária inscrita como possibilidade na natureza do Estado moderno, foi a mediação mais importante na reconstituição da totalidade (comunidade) necessária à integração social. Tal mediação torna-se clara quando os cidadãos têm a consciência do interesse público, materializando a emergência de uma esfera social que Habermas denominou repolitizada, ou Estado Social. Tal forma de Estado, conforme esse autor é capaz de aumentar seus gastos de forma sustentável no enfrentamento e ou superação das mais diferentes manifestações das desigualdades sociais.

No Brasil, mesmo que o gasto social venha aumentando progressivamente desde a década de 1990, refletido na melhoria dos indicadores de saúde e educação, as políticas redistributivas estão muito aquém dos déficits acumulados. Este paradoxo faz com que o país esteja diante dos desafios contemporâneos de construir um Sistema Único de Saúde (SUS) enquanto uma política de Estado democrático de direito, garantido pelo acesso universal, igualitário, integral, descentralizado e participativo aos serviços de saúde. Ao mesmo tempo, o país deve, em um movimento contrahegemônico, se opor à tendência de uma Sociedade-Estado de cunho neoliberal.

O modelo de Bem Estar Social desenvolvido após a Segunda Guerra Mundial, levou ao reconhecimento da saúde como direito humano. No Brasil, mais tardiamente, porém de forma inovadora, o direito à saúde, é assegurado em sua Constituição, como política permanente de Estado, assegurado como direito fundamental, de proteção social, individual ou coletivo, inscrito como direito de todos e dever do Estado, garantido mediante políticas públicas. Embora a Constituição atual tenha asseverado de forma enfática, assegurando ao cidadão o direito à saúde como direito fundamental, há uma significativa lacuna entre o seu exercício e os meios não disponibilizados adequadamente pelo Estado. Nesse sentido, o artigo 196 da CF, aduz que é dever do Estado promover ações e serviços voltados para a promoção, a proteção e a recuperação da saúde. Aduzindo ainda, o artigo 197, ser de relevância pública as ações e os serviços de saúde, quer sejam públicos ou privados, devendo ao Estado (poder público) sua regulamentação e controle.

O artigo 198 estabelece que as ações e os serviços públicos de saúde devem integrar uma rede regionalizada e hierarquizada que constituam um sistema único de saúde, da lei Constitucional nasce o Sistema Único de Saúde- SUS, organizado segundo as diretrizes da descentralização com comando único, a regionalização e hierarquização dos serviços e participação comunitária para garantir funcionamento do sistema.

A concepção e a institucionalização do SUS por meio da Constituição foram um dos maiores 
avanços na luta pela construção de um país mais justo e menos desigual. É próprio no Estado Democrático de Direito, a sociedade civil utilizar-se da reivindicação e da contestação para o exercício efetivo do direito conquistado ao longo de sua construção e no processo civilizatório, a sociedade criar estratégias de resistência e efetivação de direitos. "Os direitos se encontram no limiar de questões estruturais (normas jurídicas, instituições jurídicas ou mecanismos formais de canalização de demandas) e culturais (costumes, associativismo, solidariedade...), e sua efetivação depende diretamente de como os atores vivenciam e experienciam essas duas dimensões correferenciais."

No direito à saúde está intrínseco à integridade física e psíquica dos indivíduos, permitindo aos seus atores ver e vivenciar no seu dia a dia a relação entre as estruturas estatais, culturais e regionais. Embora constitucional, e representar um grande avanço, indicadores sociais apontam iniquidades, injustiça social e quadros epidemiológicos não favoráveis ao direito à saúde que para os autores Delduque e Oliveira ${ }^{8}$ direito à saúde não é uma realidade e permanece em construção.

\section{JUDICIALIZAÇÃO DA SAÚDE; O QUE SE DEMANDA}

O fenômeno da judicialização da saúde no Brasil se deu nos primeiros anos da década de 1990, com a grande procura ao Poder Judiciário para garantir o acesso a medicamentos, como os antirretrovirais. Das demandas por medicamentos, em que o Judiciário compeliu o gestor público a fornecer o medicamento de forma gratuita e provocou no Poder Público, a criação da política pública de distribuição gratuita de medicamentos. Foi criada a Lei no 9313/96 que garantiu a distribuição gratuita e universal dos antirretrovirais. Esperava-se que, com a criação da lei garantidora da distribuição gratuita e universal dos antirretrovirais houvesse diminuição de demandas judiciais, bem como da discricionariedade dos juízes e da interferência do judiciário no âmbito da saúde, o que não ocorreu. A autora Machado ${ }^{9}$ argumenta que antes da criação da lei, as demandas judiciais por bens e serviços de saúde eram negadas sumariamente ao passo que as demandas ajuizadas após a criação da lei passaram a ser concedidas de plano pelo Judiciário.

O fornecimento de bens e serviços de saúde vem crescendo pela via judicial. Tal crescimento é apontado por Romero ${ }^{10}$, em estudos empreendidos no Distrito Federal.

(...) a judicialização da saúde, requerida de forma individual, e coletiva acabou ganhando novos contornos e exigindo um debate mais profundo, inclusive com a entrada da instância máxima desse poder: o Supremo Tribunal Federal (STF), que, sentindo a necessidade de compreender para melhor decidir, quis ouvir os atores sociais dessa nova realidade, que desafia a refletir e impulsiona para novas condutas. Desse modo, instalou a Audiência Pública em que foram ouvidos 50 especialistas, entre advogados, defensores públicos, promotores e procuradores de justiça, magistrados, professores, médicos, técnicos de saúde, gestores e usuários do SUS, nos dias 27, 28 e 29 de abril, e em 4, 6 e 7 de maio de 2009. Dessa Audiência Pública surgiram as recomendações do Conselho Nacional de Justiça, para que os Tribunais Estaduais passassem a decidir de forma homogênea e conhecedora do SUS e para que, com 
isso, pudessem aprofundar a discussão dos rumos da judicialização da saúde no Brasil ${ }^{11}$.

Após 27 anos da promulgação da constituição cidadã que positivou o direito à saúde como direito fundamental, e após 19 anos da lei que garantiu de forma gratuita e universal a distribuição de medicamentos, ainda se judicializa por bens e serviços de saúde, entre eles, medicamentos. Mesmo com o avanço das políticas públicas, a via judicial é largamente utilizada para garantir e concretizar o direito e suscitar políticas públicas.

Ao Estado cabe, através de seus órgãos e poderes constituídos, assegurar o exercício pleno da cidadania a todos os cidadãos, para que assim prevaleça a dignidade da pessoa humana e o estado democrático de direito.

A judicialização da saúde por medicamentos ainda acontece mesmo depois da criação em 1996 da política pública que garante a distribuição gratuita e universal de medicamentos. As demandas judiciais também se dão por medicamentos já inclusos na Relação Nacional de Medicamentos Essenciais (RENAME). Essa realidade precisa ser revista uma vez que a maioria das demandas judiciais é acompanhada de receituários assinadas por profissionais do próprio serviço público de saúde. Para Marçal ${ }^{12}$, resta investigar se o profissional desconhece a RENAME ou a RENAME não atende as necessidades terapêuticas dos usuários.

Há ainda demandas judiciais por medicamentos de alto custo não constantes na RENAME. Estudos realizados por Medeiros ${ }^{13}$ apontam que empresas distribuidoras de medicamentos e indústrias farmacêuticas interessam-se por patrocinar ações judiciais em que se requer medicamentos de alto custo, bancando para o usuário os honorários de advogados particulares, para ingressarem com o pedido em juízo.

Não apenas por medicamentos acontece a judicialização na saúde. Ela se dá para assegurar o exercício pleno da cidadania e respeito à dignidade da pessoa humana. Em recente estudo ${ }^{14}$, apontaram alguns bens requeridos por usuários no Estado de São Paulo: fraldas, alimentação parental, suplemento alimentar, transporte para o deslocamento ao local do tratamento e o medicamento que lidera o rankig das demandas. Não há como não questionar a gestão da saúde concernente à política de distribuição de medicamentos, criada há quase duas décadas e não atender de forma satisfatória aos usuários do SUS que pleiteiam medicamentos contemplados pela política e constantes na RENAM.

Em algumas unidades da federação, as demandas judiciais por medicamentos perdeu o foco. É o que apontam estudos recentes realizados no Distrito Federal em que o objeto das demandas judiciais é leito hospitalar ${ }^{13}$. A concessão de limar em demandas por leito hospitalar é geradora de iniquidade, uma vez que com um mandado para cumprir de imediato sob pena de prisão, de responsabilidade e ou de multa de valor considerável, o profissional de saúde do serviço público se vê numa situação constrangedora. Não havendo leito disponível e com uma decisão judicial para cumprir, o profissional responsável terá que decidir qual o paciente deixará de receber o 
tratamento e os cuidados necessários para dar lugar ao contemplado com a decisão judicial. Ainda há os que não requereram o leito por via judicial e não obstante precisam mais urgentemente do que aquele. Assim, o princípio da equidade que baliza o SUS é atropelado pela mesma justiça que em caso adverso empoderou o cidadão, neste caso, concedendo a um o seu direito, que para seu cumprimento, destitui o direito do outro.

\section{INSTITUTO DA MEDIAÇÃO ESTRATÉGIA À DESJUDICIALIZAÇÃO DA SAÚDE}

Diante da enorme lacuna existente entre o exercício do direito à saúde e os meios que não são disponibilizados adequadamente pelo Estado, a judicialização da saúde ocorre em todo país provocando crise no judiciário que por si só já não se faz suficiente para atender a larga demanda que não para de crescer e não solucionando os conflitos com a celeridade e eficiência que se exige no âmbito da saúde, urge a necessidade de meios eficientes para a solução de conflitos também de ordem social.

Cappeletti e Garth ${ }^{15}$, em sua obra "Acesso à Justiça", nos brindam com preciosas contribuições para enfrentar o grave problema, dentre as quais se destacam: a assistência judiciária gratuita aos mais vulneráveis, no Brasil, essa função é assumida pela Defensoria Pública; as ações coletivas que tratam os direitos difusos, patrocinadas pelo Ministério Público; soluções alternativas à jurisdição, a mediação, tema deste estudo, recentemente normatizada em nosso país, já trazendo em si, a expectativa positiva de ser meio eficaz para resolução de conflitos, em especial os de ordem da saúde.

A Mediação é um meio extrajudicial de resolução de conflitos, no qual um terceiro é chamado para encaminhar as partes para chegarem a uma solução ou acordo, é um método alternativo de solução de conflitos, uma forma de exercício de cidadania e efetividade ao acesso à justiça. Recentemente foi sancionada a Lei 13.140 que trata da Mediação e que tem o objetivo de desafogar os Tribunais que lidam com mais de 95 milhões de processos em tramitação e que podem chegar a alcançar a marca de 114,5 milhões em 2020, segundo o CNJ. Espera-se com a prática da mediação, a diminuição de demandas judiciais nos tribunais brasileiros.

Quanto às demandas por bens e serviços de saúde, estas são provocadas mediante problemas do Sistema de Saúde que deve avocar para si a responsabilidade de solucionar os conflitos por ele gerados.

Para Delduque e Castro ${ }^{16}$, é necessário adotar uma nova prática e nova cultura no âmbito do SUS. Permanecer vigilante aos modos de conflitos e instituir a mediação sanitária dentro do sistema.

Sobre a mediação sanitária, nos ensina Delduque e Castro que:

A Mediação Sanitária é um modelo alternativo de resolução de conflitos na área da saúde. As relações em saúde transcendem a ótica bilateral do médico com o paciente, para envolver muitos 
outros atores presentes em um sistema de saúde, advindo, daí, conflitos de toda a ordem, internos e externos ao sistema, criando condições para a judicialização. Conflitos internos (como os assistenciais, organizativos e conflitos entre profissionais) geram desgastes e judicialização, como também fazem os conflitos gerados fora do sistema, mas com reflexos diretos dentro dele, assim como os conflitos sociais e conflitos legais igualmente geram a judicialização. ${ }^{16}$

Nessa construção, os conflitos gerados por falta do cumprimento do preceito constitucional que garante o direito a saúde, são conflitos do Sistema, devendo ser tratados pelo próprio Sistema de Saúde por meio da mediação sanitária.

\section{CONCLUSÃO}

Sendo saúde é um direito fundamental à vida, positivado na Constituição Federal de $1988^{1}$. É prerrogativa do Poder Público criar políticas públicas para dar cumprimento às atribuições do Estado, insertas na CF. Assim, o cidadão estará a exigir do Estado por da prestação jurisdicional a concretude do seu direito. A sociedade evolui e surgem novos direitos atrelados a novos deveres.

$\mathrm{Na}$ conjuntura atual, os Tribunais brasileiros abarrotados de processos, já não dão conta de solucionar as demandas com a celeridade que se requer pela largo volume de ações e pelos novos direitos sociais que surgem exigindo também novas formas de resolução de conflitos.

A mediação sanitária desponta como instrumento de resolução de conflitos, em resposta ao cidadão que almeja de forma célere a efetivação do seu direito à saúde. Através do diálogo as partes conhecem as razões, os limites e buscam encontrar a solução de suas demandas no próprio Sistema, ocorrendo assim a desjudicialização da saúde.

\section{REFERÊNCIAS BIBLIOGRÁFICAS}

1. BRASIL. Constituição (1988). Constituição da República Federativa do Brasil. 35. ed. Brasília, DF: Senado Federal, 2012.

2. Brasil. Lei no 8.080, de 19 de setembro de 1990. Dispõe sobre as condições para a promoção, proteção e recuperação da saúde, a organização e o funcionamento dos serviços correspondentes e dá outras providências. Diário Oficial [da] União. Brasília DF, 19 set. 1990.

3. SOUSA, MF \&Hamann, EM- Saúde da Família no Brasil: estratégia de superação da desigualdade na saúde? Physis vol.19 no. 3 Rio de Janeiro 2009.

4. FLEURY, S. Estados sem cidadãos. Rio de Janeiro: Fiocruz, 1994.

5. BOBBIO, Norberto. A era dos direitos. Rio de Janeiro: Campus, 1993. 
6. ARENDT, H. A Condição Humana, São Paulo: Forense Universitária, 1993.

7. ASSENI, F. D. Saúde, Poder, Judiciário e Sociedade. Physis. 2013, 23 [3]: 801-820, 2013.

8. DELDUQUE, M. C.; OLIVEIRA, M. S. C. Tijolo por tijolo: a construção permanente do direito à saúde. In: $\operatorname{COSTA}, \mathrm{A}$. $\mathrm{B}$. et al. (Org.) O Direito achado na rua: introdução crítica ao direito à saúde. Brasília: CEAD/ UnB, 2009. p. 103-111.

9. MACHADO, M. A. A. et al. Judicialização do acesso a medicamentos no Estado de Minas Gerais, Brasil. Rev. Saúde Pública, Rio de Janeiro, v. 45, n. 3, p. 590-598, 2011.

10. ROMERO, L. C. Judicialização das políticas de assistência farmacêutica: o caso do distrito federal. Textos para discussão 41. 2008. Disponível em: <http://www. senado.gov.br/ senado/conleg/textos_discussao/TD41LuizCarlosRomero.pdf>. Acesso em: 14 abr. 2015.

11. OLIVEIRA, M. R. M. A judicialização da saúde no Brasil. Tempus Actas de Saúde Coletiva, Brasília, DF, v. 7, n. 1, p. 79-90, abr. 2013.

12. MARÇAL, K. K. S. A Judicialização da AssistênciaFarmacêutica: o caso Pernambuco em 2009 e 2010. 2012. 125 f. Dissertação (Mestrado em Saúde Pública) - Centro de Pesquisas AggeuMagalhães, Fundação Oswaldo Cruz, Recife, 2012.

13. MEDEIROS, M.; DINIZ, D.; SCHWARTZ, I. V. D. A tese da judicialização da saúde pelas elites: os medica- mentos para mucopolissacaridose. Ciênc. saúde Colet., Rio de Janeiro, v. 18, n. 4, p. 1079-1088, 2013.

14. OLIVEIRA, M, R, M. Judicialização da saúde: para onde vão as produções científicas? Rev. Saúde Debate v. 39, n. 105, p. 525-535, 2015.

15. CAPPELletTI, M; GARTH, B. Acesso à justiça. Trad. Ellen gracieNorthfleet. Porto Alegre: Sérgio Antonio Fabris Editor, 1988.

16. DELduQue, M. C; CASTRO, E, C. A Mediação Sanitária como alternativa vieavel à judicialização das políticas de saúde. Rev. SAÚDE DEBATE V.39, n. 105, p. 506-513, 2015.

Artigo apresentado em 15-08-15

Artigo aprovado em 21-02-16

Artigo publicado no sistema em 22-03-16 